\title{
TMS President Wolfgang Schneider: Looking Forward to TMS- The Innovative Materials Society
}

\author{
Wolfgang Schneider
}

As I am publishing my first Presi-

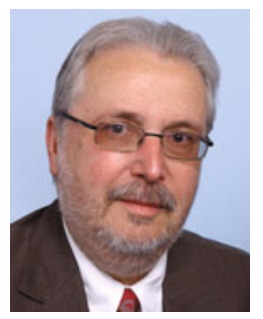
dential Perspective in the month of the TMS 2012 Annual Meeting, it is appropriate that I ask: What do the numbers 35 and 52 tell Wolfgang Schneider you? The answer: $35 \%$ of TMS members are from outside the United States, and, on average, $52 \%$ of the attendees at the TMS Annual Meeting are from outside the United States. This distinctively shows that TMS has become an international society. Clearly, the ever increasing number of international members and conference participants proves that TMS attracts materials scientists from all over the world by its offered products and services. This also means that TMS is increasingly subjected to international competition. To meet this competition, and to play a leading role in the profession, the society will have to develop continuously and expediently. Thus, the importance of developing new products and new services cannot be underestimated; innovation is the key for a successful future. This is valid not only for successful industry enterprises, but also for successful nonprofit organizations such as TMS. Therefore the goal must be to become: TMS - The Innovative Materials Society.

How can this goal be achieved? Innovation today can be distinguished as "Closed" and "Open." Closed Innovation means that new ideas are generated only internally, within the organization, whereas the Open Innovation approach uses the world for

\section{ABOUT THE PRESIDENT}

Wolfgang Schneider is head of the research and development center of Hydro Aluminum Rolled Products Business in Bonn, Germany. He is also a professor of metallurgy at the Technical University of Berlin, and has been a TMS member since 1996 .

idea generation. Today many companies worldwide use this approach, also called Crowd Sourcing, systematically and successfully. As a volunteer-driven organization TMS is tailor-made for Open Innovation. TMS has more than 12,000 members worldwide, many of whom certainly have good ideas for new products and new services for TMS. Applying open innovation to our society, the members themselves can share their expectations from TMS, and ideas for innovation, in the future.

In what areas are innovations of significance for TMS? Although some might argue that innovation is essential to all we do as a professional society, for practical purposes we must narrow our focus. During discussions of the revised TMS Strategic Plan last year, key focus areas were identified as volunteerism, education, products and services, and information. Therefore work on innovations in these areas should be a priority. As a consequence, for the coming term, a set of goals and activities was identified to develop the organization further.

In the area of volunteerism, the focus will be on the technical divisions and committees, recognizing that the majority of programming and other volunteer support comes through these groups. Through strategic planning and possible structural changes, we will try to strengthen the innovative force of the divisions. An improvement of the communication from the board to the technical volunteers and vice versa is also considered.

In education, the goal is to develop new approaches through revision of the current strategy and benchmarking with other models. Here, considerable growth potential persists as the importance of continuing education is increasing.

From an innovative perspective, it is important that the current product and service portfolio be analyzed and adjusted, with the addition of new products and also the elimination of old products. We must also seek ways to sustain and grow the core areas of TMS.

Finally, we will investigate new ways of information distribution to make the work of the society and also the work of the board more efficient and transparent for volunteers and members.

These are ambitious goals for the coming years that cannot be accomplished without the full support of our membership. Therefore I invite you to a dialogue. Give us your ideas for an effective and sustainable future of TMS, the materials society of your choice - the Innovative Materials Society.

Allow me to end this perspective with a simple slogan which corresponds to a song title of the Woodstock veterans Canned Heat, who in 1970 scored a worldwide hit with it. This is: "Let's work together." So I implore you: "Let's work together" for the benefit of TMS and for the benefit of the materials community. 